\title{
To Walk or Not to Walk
}

\author{
Raja Noriza Raja Ariffin ${ }^{1}$, Rustam Khairi Zahari² \\ 1 University of Malaya, Kuala Lumpur 50603, Malaysia \\ 2 International Islamic University, Jalan Gombak, Kuala Lumpur 50728, Malaysia \\ rnoriza@um.edu.my, rustam@iium.edu.my
}

\begin{abstract}
Walkability is the basis of a sustainable city. Walking is the socially equitable mode most accessible to the masses. However, the advent of transportation technology has caused the desertion of the pedestrian space. Consequently, the phenomenon created a degradation of the pedestrian environment. The aim of the paper is to examine the characteristics that could promote walking. This paper combines survey questionnaire and walkability audit to gauge perception of the urban walking environment. Findings indicate that the proximity of destinations, good weather condition, safety and well-designed pedestrian facilities can significantly contribute to better perceptions of the walking environment.
\end{abstract}

Keywords: Walkability; sustainable transport; perceptions; pedestrian

eISSN 2398-4295 @ 2018. The Authors. Published for AMER ABRA cE-Bs by e-International Publishing House, Ltd., UK. This is an open-access article under the CC BY-NC-ND license (http://creativecommons.org/licenses/bync-nd/4.0/). Peer-review under responsibility of AMER (Association of Malaysian Environment-Behaviour Researchers), ABRA (Association of Behavioural Researchers on Asians) and CE-Bs (Centre for EnvironmentBehaviour Studies), Faculty of Architecture, Planning \& Surveying, Universiti Teknologi MARA, Malaysia.

http://dx.doi.org/10.21834/ajbes.v3i11.114 


\subsection{Introduction}

Walkability is the basis of a sustainable city. Walking is the socially equitable mode most accessible to the masses. It is also the most environmentally friendly transportation model. However, the advent of transportation technology, such as automobile and superhighway has degraded the pedestrian environment. As a result of degradation, the pedestrian environment lost its intimate scale and became devoid of public life. Of late, the health benefits of walking have led to extensive research on the influence of the built environment on travel mode.

Many studies have shown that characteristics of the pedestrian environment play a major role in determining the respond from users. Although there is growing evidence that the neighbourhood environment can influence walking in many western countries, the amount of such evidence is limited in Malaysia. Against this backdrop, the aim of the paper is to examine the characteristics or attributes that could promote walking activity. This article gives insights as to how future efforts in promoting walking need to address several aspects of the urban environment.

\subsection{Literature Review}

Walking is the most primary form of transporting (Grignaffini et al., 2008). Walkability is a measure of how friendly an area is to walking. The walkability of a neighbourhood can be measured by identifying the walking behaviour of the residents to community facilities (Azmi and Abdul Karim, 2013). The benefits of walking can be discussed from three perspectives: economic benefits, social benefits and environmental benefits (Litman, 2004). From the economic perspective, walking can improve accessibilities especially for the non-drivers, hence reducing transportation cost. In term of social benefits, walking can increase neighbourhood interaction and community cohesion. It also improves the opportunity to preserve cultural resources and safeguard the aesthetic of an area. Likewise, walking can be beneficial to the environment by reducing the use of land for roads and parking facilities and reducing energy consumption and pollutions. On the same notes, Cubukcu (2013) illustrates walkable localities as places that are designed for people, retain a sense of history and place, connects people to destinations and nature, and honours social and environmental diversity. These environments will consequently improve the quality of life of the inhabitants.

Findings from some studies show that improving the built environment did not cause people to walk more (Shokoohi et al., 2011). However, there are other studies that stated otherwise. As an example, Parks and Schofer (2006) mention that network design helps determine the ability of pedestrians to reach their destinations. According to them, grid networks with short blocks allow for relatively direct routes, while long blocks and curvilinear streets lengthen pedestrian trips by requiring circuitous routes. Sidewalks are also an essential component of good pedestrian design in areas where automobile traffic is quite heavy. Lack of sidewalks implies pedestrians must either walk in the roadway, which decreases safety, or walk alongside the road in an unfriendly environment. 
Researchers in planning and transportation have identified land-use mix, residential density and street connectivity as the fundamental aspects for creating walkability indices (Frank and Pivo as cited in Leslie, 2005). Higher population density, greater connectedness of streets and mixed land use has also been linked with higher rates of walking and bicycling trips for transportation (Saelens et al. as cited in Leslie, 2005). A study undertaken by Hosseini et al. (2012) in Dardasht District, Iran, also found that street connectivity is associated with pedestrian use.

Walkability can be interpreted as a match between residents' desires and expectations (Manaugh, 2011). It is further noted that neighbourhoods that find this match between built form and residents' needs will likely have more people walking in them. Similarly, a study undertaken by Gebel et al., (2011) shows the importance of perception in encouraging people to walk. It concluded that those who misperceived their neighbourhood to be less walkable can negatively and significantly affect their walking for transport and for leisure.

Other than the built environment, weather conditions are shown to affect walking. The results concerning the weather variables find that average temperature and total precipitation impact walking (Clark et al., 2013). This study undertaken in Canada suggests that increasing walking as a mode of transport might be difficult to achieve in climates where there are consistently low temperatures or high amounts of precipitation. Lighting, footway width, footway gradient, weather, proximity to transport facilities or signage show a high degree of importance in encouraging people to walk in a study done by Campos et al. (2003). Both of the studies by Clark et al. (2013) and Campos et al. (2003) were conducted in countries with cold climate, therefore the weather mention in the studies was associated with coldness. However, a study done in Hong Kong, which experience higher temperature than Canada and the United Kingdom also found that the respondents suggested that having a weather proof environment can satisfy their needs as pedestrian (Hung et al., 2010)

Other than the built environment and weather conditions, safety is also a point of concern for pedestrian. Individuals who live in area that are more walkable and have lower crime rates tended to walk more (Doyle et al., 2007). There are many studies that correlate safety to the rate of walking. Appleyard (2003) for example, illustrated that pedestrian activity is associated with the level of personal safety within a neighbourhood.

\subsection{Methodology}

This paper combines survey questionnaire and walkability audit to gauge perception of the urban walking environment. The respondents for the survey questionnaire came from several neighbourhoods in the Klang Valley. The survey questionnaire gauges residents' perceptions and attitudes about the pedestrian environment. A total of 155 survey questionnaires were distributed to the neighborhoods in Petaling Jaya, Kuala Lumpur and Putrajaya. The respondents were randomly selected among the residents of the neighborhoods. Finally, 126 survey questionnaires were used in the analysis.

Walkability audit identifies concerns for pedestrians related to safety, access, comfort, and convenience of the walking environment. It is an assessment of the walkability or 
pedestrian access of the external environment. A good walking audit can deliver tailor-made recommendations on how to improve street environments and utilise the resources on a maximum level in planning the urban environment.

There are several processes of walking audit and they can be tailored to suit the stakeholders. For this research, students of a postgraduate level class in urban management were engaged to conduct the walkability audit. The first step was reviewing several audit guides. Next, the class had a discussion on the criteria and the conduct of the audit to standardise and orientate their perceptions of the walking environment. The students were then divided into six groups to cover several areas in the Klang Valley. The main activities of the walkability audit for this research are observation and image recording. The data from the walkability audit and the survey questionnaire were then triangulated to give credibility and validity to the research findings.

\subsection{Results and Discussions}

Many studies have shown that walking frequency is very much influenced by the built environment. The studies show that a conducive environment for walking would attract active walking. Hence, one of the survey questions was to gauge the frequency of walking to examine the level of walking activity among the respondents.

Table 1. Survey results on respondents' walking frequency.

\begin{tabular}{ccc}
\hline Frequency of walking & Frequency & Percentages \\
\hline Everyday & 80 & 63.5 \\
2-3 times a week & 25 & 19.8 \\
Once a week & 11 & 8.7 \\
Sometimes (less than once a week) & 7 & 5.6 \\
Never & 3 & 2.4 \\
Total & 126 & 100 \\
\hline
\end{tabular}

(Source: Field survey, 2013)

Table 1 shows that the majority of the respondent ( 63.5 percent) walk every day, while 19.8 percent walk between 2 to 3 times a week. A much smaller percentage ( 8.7 percent) of the respondents walks once a week, while 5.6 percent walk sometimes. Only 2.4 percent of the respondents chose 'never' as their frequency of walking. Although the result does not establish the walking distance, it shows that majority of the respondents walk frequently.

Table 2. Survey results on respondents' activities/destination for walking.

\begin{tabular}{ccc}
\hline Activities/Destination & Frequency & Percentages \\
\hline For shopping/errands & 67 & 53.2 \\
To get to work & 51 & 40.5 \\
For exercise/health & 42 & 33.3 \\
To get to school/college & 37 & 29.4 \\
\hline
\end{tabular}


To get to the bus stop

For pleasure/to walk pets
32

30
25.4

23.8

(Source: Field survey, 2013)

On why and where they walk, the respondents can choose more than one answer from a given list of attributes. The results show that the majority (53.2 per cent) walks to do shopping/errands (Table 2). The next popular choice on the reason for walking is 'to get to work' (40.5 percent). 33.3 percent walk for exercise/health, while 29.4 percent of the respondents walk to get to school/college. 'To get to the bus stop' registered 25.4 percent of respondents and finally, 23.8 percent of the respondents walk for pleasure/to walk pets.

Table 3. Survey results on the factors that prevented the respondents from walking more often.

\begin{tabular}{ccc}
\hline Attributes & Frequency & Percentages \\
\hline Places too far away & 56 & 44.4 \\
Crime Issues & 47 & 37.3 \\
I have to carry things & 44 & 34.9 \\
Weather is not good & 40 & 31.8 \\
Too many cars & 21 & 16.7 \\
Cars drive too fast & 21 & 16.7 \\
Travel with small children & 20 & 15.9 \\
Drivers don't stop & 18 & 14.3 \\
No sidewalk & 17 & 13.5 \\
Sidewalk in poor condition & 16 & 12.7 \\
Difficult to cross the street & 15 & 11.9 \\
No kerb ramps & 8 & 6.4 \\
Not enough lighting & 8 & 6.4 \\
\hline
\end{tabular}

(Source:Field survey, 2013)

The next fundamental question to gauge people perception in order to provide a better walking environment is the scenario that prevents them from walking. Similar to the previous question, the respondents can choose more than one answer to the question on what prevent them from walking more often. Table 3 indicates that the majority (44.4 percent) cited 'places too far away' as the reason that prevents them from walking more often. The next popular choice is 'crime issues' with 37.3 percent stated this as the reason for walking less often. 34.9 percent cited 'I have to carry things', while 31.8 percent stated 'weather is not good' as the reason that prevented them from walking more often. There are not many differences in term of percentages registered for other attributes such as 'too many cars', 'cars drive too fast', 'travel with small children' and 'drivers don't stop'. For the attributes 'no sidewalk' and 'sidewalk in poor condition', both registered quite a similar number of respondents; 17 (13.5 percent) and 16 respondents (12.7 percent) respectively. Both 'no kerb ramps' and 'not enough lighting' are cited by only 6.4 percent of the respondents as the attributes that prevented them from walking more often.

As shown in Table 3, 'places too far away' registered the highest percentage on the question of what prevents them from walking more often. People would be more likely to 
perceive a destination as far away when there are not many interesting activities along the way. Several studies have shown that mixed land use and greater connectedness of streets are linked to higher rates of walking. In this context, short blocks allow for relatively direct routes and small building setbacks make commercial establishment and resident easily accessible to pedestrian. All of this scenario can have an impact on people's perception of travel distance.

Density is another factor that makes places to be far away from one another. According to Kenworthy and Laube (as cited in Barter 2004), the urban density for Klang Valley is low with 58 persons per hectare. Table 5 shows the density for new development in the Klang Valley. According to a study done by Newman and Hogan (cited in Hashim 2004), the minimum density to encourage people to walk to daily activities is 130 to 400 persons per hectare. Therefore, the densities for new development in Klang Valley clearly illustrate that it does not cater to the needs of a walkable community.

Table 5. Density for new development in the Klang Valley

\begin{tabular}{cccc}
\hline New Township & Size (hectare) & Population & Density (person/hectare) \\
\hline Putrajaya & 4,581 & 300,000 & 10.9 \\
Cyberjaya & 7,001 & 370,000 & 8.8 \\
Bukit Jelutong & 892 & 31,068 & 5.8 \\
Kota Kemuning & 736 & 32,715 & 7.3 \\
Berjuntai Bistari & 11,736 & 500,000 & 7.1 \\
\hline
\end{tabular}

(Source: Adapted from Hashim, 2004)

Another important question to look into the need of the respondent is their motivation to walk. In this case, the circumstances that would encourage them to walk must be explored so that a better walking environment could be provided. Using the same method as the previous two questions, the respondents are given the option to choose more than one answer from a given list of attributes. The results in Table 4 show that the majority (55.6) cited 'weather is good' as the circumstance that encourage them to walk. This is followed closely by 'less risk from crime' with 54.8 percent. 'Sidewalk in good condition' is another prerequisite that carry a high percentage with 46.0 percent of respondents opted for that. 30.2 percent of the respondents cited 'less car on the street' as the reason that could motivate them to walk. 'Wide sidewalk' and 'enough lighting' registered almost the same number of respondents; 35 (27.8 percent) and 34 (27.0 percent) respondents respectively. 21.4 percent of the respondents chose 'can find many amenities/activities along the way' as the attribute that could encourage them to walk, while 19.8 percent of the respondents cited 'good traffic signal/signage for pedestrian' as their preferred scenario that would motivate them to walk. Surprisingly, 'cars are slow' seems to be a less popular attribute that could encourage the respondents to walk (18.3 percent). 
Table 4. Survey results on the factors that encourage the respondents to walk.

\begin{tabular}{ccc} 
Attributes & Frequency & Percentage \\
\hline Weather is good & 70 & 55.6 \\
Less risk from crime & 69 & 54.8 \\
Sidewalk in good condition & 58 & 46.0 \\
Less car on the street & 38 & 30.2 \\
Wide sidewalk & 35 & 27.8 \\
Enough lighting & 34 & 27.0 \\
Can find many amenities/activities along the way & 27 & 21.4 \\
Good traffic signal/signage for pedestrian & 25 & 19.8 \\
Cars are slow & 23 & 18.3 \\
\hline
\end{tabular}

(Source: Field survey, 2013)

'Weather is good' registered the highest percentage in the survey question related to the attributes that would encourage the respondents to walk. This shows that weather plays a fundamental role that could motivate the respondent to walk. According to Setyowati et al. (2013), a comfortable pedestrian design should be able to anticipate the negative impacts of local climates, such as heat, humidity, rainfall and wind speed. Studies in other countries have also demonstrated the importance of weather condition in encouraging people to walk. Therefore, the fluctuation of the Malaysian climate could pose a serious threat to pedestrians and walkability agenda. In fact, among the top scenario that prevented the respondents from walking is the bad weather.

One of the key components of a walkable neighbourhood is the sidewalk. Several studies have shown that sidewalks play a role in creating a pedestrian friendly area. As an example, a study done by Shamsuddin et al. (2013) in Kuala Lumpur shows that majority of the respondents agree that pedestrian walkways are the most important element needed to encourage walking activities in the city. During the walking audit it was found that several important aspects of sidewalks that would encourage people to walk are not implemented. Many of the areas are either without proper sidewalks or are in bad condition. The sidewalks are narrow and the existence of street furniture makes them even narrower. In several places, the sidewalks are not continuous, prompting pedestrian to walk on a dangerous road or terrain. In Putrajaya, however, the walkability agenda seems to be achievable. However, it was observed that the pedestrian pathways were not fully utilised. Most of the walkways are deserted and under-utilised. The result of the survey questionnaire shows that the presence of many amenities and activities along the pedestrian walkway can help in encouraging the respondents to walk. Thus, the lack of activities along the walkway in Putrajaya may contribute to this state of affairs.

Crime is also one of the factors that discourage people from walking. The study result pointed that 'less risk from crime' is one of the criteria that motivate people to walk. Besides, 'crime issues' was also a popular choice among the respondent when asked on the attributes 
that would prevent them from walking more often. Findings from many studies have indicated the importance of safety or perception of safety in encouraging people to walk.

Since this is only a preliminary study of looking at people perception of the urban walking environment in the Klang Valley, there are limitations involved. The limitation of the study is that it does not associate demographic background of the respondents with their perception of the urban walking environment. This is an important consideration since a study by Azmi et al. (2013) shows that in designing a neighbourhood towards a walkable environment, the average walking distance for every different age group of residents must be taken into consideration. The result demonstrates the importance of considering demographic background to understand pedestrians' needs. Future study would include these acknowledged limitations.

\subsection{Conclusion}

This paper presents the findings of a study combining walkability audits and a survey-based respondent to examine the influence of built environment characteristics on people's perceptions of the urban walking environment. Findings indicate that proximity of destinations, good weather condition, safety and well-designed pedestrian facilities can significantly contribute to better perceptions of the walking environment. In planning a walkable city to promote sustainable transport in the Klang Valley, planners should look into a plan that promotes crime prevention and safety, proximity of destinations and environment that provide ease of walking.

\section{References}

Appleyard, B. S. (2003). Planning safe routes to school. How will my child get to and from school? Planning, 69(5), 34.

Barter, P.A. (2004). Transport, urban structure and lock-in in the Kuala Lumpur Metropolitan Area. International Development Planning Review, 26(1), 1-24.

Clark, A. F., Scott, D. M. \& Yiannakoulias, N. (2013). Examining the relationship between active travel, weather, and the built environment: A multilevel approach using a GPS-enhanced dataset. Transportation.

Campos, M.B., Chiaraida, A., Smith, A., Stonor, T. \& Takamatsu, S. (2003). Towards a 'walkability index'. Proceedings of the European Transport Conference. Online 24th June 2013. http://trid.trb.org/view.aspx?id=771383.

Cubukcu, E. (2013). Walking for Sustainable Living, Procedia - Social and Behavioral Sciences, 85, 33 - 42.

Doyle, S., Kelly-Schwartz, A., Schlossberg, M.\& Stockard, J. (2006). Active Community Environments and Health: The Relationship of Walkable and Safe Communities to Individual Health. Journal of the American Planning Association, 72(1), 19-31. 
Gebel, K. Bauman, A. Sugiyama, T. \& Owen, N. (2011). Mismatch between perceived and objectively assessed neighborhood walkability attributes: Prospective relationships with walking and weight gain. Health and Place, 17(2), 519-524.

Grignaffini, S., Cappellanti, S. \& Cefalo, A. (2008). Visualizing sustainability in urban conditions. WIT Transactions on Ecology and the Environment, 1, 253-262.

Hashim, N. (2004). Urban Development and Transport Planning in Malaysia - Present Practice. Paper presented at Air Pollution Control for Malaysian Cities Seminar, 17-18 February 2004, Hyatt Regency, Kuantan.

Hosseini, S.B., Maleki, S.N. \& Azari, A.K. (2012). The Influences of Access Improvements in Pedestrian Street Use, Procedia - Social and Behavioral Sciences, 35, 645 - 651.

Hung, W. T, Manandhar, A. \& Ranasinghege, S A, (2010). A Walkability Survey in Hong Kong. TRANSED 2010: 12th International Conference on Mobility and Transport for Elderly and Disabled Persons, 1-4 June, 2010.

Leslie, E. Saelens, Frank, L., Owen, N. Bauman, A. Coffee, N. \& Hugo, G. (2005). Residents' perceptions of walkability attributes in objectively different neighbourhoods: a pilot study. Health and Place, 11(3), 227-236.

Litman, T. (2004). Economic Value of Walkability. World Transport Policy and Practice, 10(1), 5-14.

Manaugh, K. \& El-Geneidy, A. (2011). Validating walkability indices: How do different households respond to the walkability of their neighborhood? Transportation Research Part D: Transport and Environment, 16(4), 309-315.

Parks, J. R. and Schofer J.L. (2006). Characterizing neighborhood pedestrian environments with secondary data. Transportation Research Part D, 11, 250-263.

Setyowati, E., Harani, A.R. \& Falah, Y.N. (2013). The Application of Pedestrian Ways Design Concepts as an Implementation of Sustainable Urban Open Spaces, Procedia - Social and Behavioral Sciences, 85, 345 - 355. 